\section{Discrete Mathematics in Primary and Secondary Schools in the United States}

\author{
Valerie A. DeBellis, Durham, NC (USA) \\ Joseph G. Rosenstein, New Brunswick, NJ (USA)
}

\begin{abstract}
This article provides a status report on discrete mathematics in America's schools, including an overview of publications and programs that have had major impact. It discusses why discrete mathematics should be introduced in the schools and the authors' efforts to advocate, facilitate, and support the adoption of discrete mathematics topics in the schools. Their perspective is that discrete mathematics should be viewed not only as a collection of new and interesting mathematical topics, but, more importantly, as a vehicle for providing teachers with a new way to think about traditional mathematical topics and new strategies for engaging their students in the study of mathematics.
\end{abstract}

Kurzreferat: Der Artikel beschreibt, wie Inhalte der Diskreten Mathematik im Curriculum amerikanischer Schulen berücksichtigt werden. Er gibt darüber hinaus einen Überblick über relevante Forschungsprogramme und einschlägige Publikationen zu diesem Thema. Die Autoren diskutieren, warum die Diskrete Mathematik in der Schule unterrichtet werden sollte. Es geht nicht nur darum, dass damit neue und interessante Inhalte vermittelt werden können. Vielmehr ist die Diskrete Mathematik geeignet, Lehrerinnen und Lehrern ein neues Bild von Mathematik zu vermitteln. Diese Sichtweise ist geeignet, Schülerinnen und Schüler für mathematisches Arbeiten zu motivieren.

\section{ZDM-Classifikation: B70, D30, E40, N70}

\section{Overview}

The introduction of discrete mathematics in primary and secondary schools in the United States (referred to in this article as K-12 schools ${ }^{1}$ ) was encouraged and facilitated by the recommendations of the National Council of Teachers of Mathematics (NCTM) in the Curriculum and Evaluation Standards for School Mathematics (1989). John Dossey provides historical background for these recommendations in his article, Discrete Mathematics: The Math for Our Time (1991). He describes the emergence of discrete mathematics as a separate area of study beginning in the late 1960s with influential texts appearing at the upper undergraduate level throughout the 1970s

\footnotetext{
${ }^{1}$ The terms "primary" and "secondary" are not used as widely in the United States as elsewhere, and, when used, do not have the same meaning as in other countries, because most American school systems involve three levels, rather than two. The terms used to describe specific schools are "primary school" (for grades Kindergarten to 3), "elementary school" (usually grades $\mathrm{K}$ to 4 or 5), "middle school" or "intermediate school" (usually grades 5 or 6 to 7 or 8 ), "junior high school" (usually grades 7 to 9), and "high school" (grades 9 or 10 to 12). The entire system is often referred to as " $\mathrm{K}-12$ " to reflect the thirteen years of schooling provided from kindergarten ( 5 years of age) to grade 12 (18 years of age).
}

(Bondy and Murty 1976, Liu 1968, Roberts 1976, Stanat and McAllister 1977, and Tucker 1980). Recommendations followed for the inclusion of discrete mathematics in programs of study for undergraduate mathematics majors. By 1983, the effects of the new college curriculum on high school mathematics were being considered (Maurer, 1983), and additional recommendations on the need to develop ideas of discrete mathematics earlier in the mathematics curriculum were being discussed. The report of the Conference Board of the Mathematical Sciences (CBMS), The Mathematical Sciences Curriculum K-12: What Is Still Fundamental and What Is Not (1983), along with the NCTM report, Computing and Mathematics: The Impact on Secondary School Curricula (Fey, 1984), called for the incorporation of discrete mathematics in the school mathematics curriculum. An NCTM report, Discrete Mathematics and the Secondary Mathematics Curriculum (Dossey, 1991), outlined the discrete mathematics topics appropriate for grades 7-12.

The Curriculum and Evaluation Standards for School Mathematics (1989) was intended to set standards for what mathematics all students should know, understand and be able to do in three grade bands, K-4, 5-8, and 912. In this document, referred to informally as "the NCTM standards" or simply as "the standards," "discrete mathematics" was a separate curriculum standard for grades 9-12. Some discrete mathematics topics appeared in the grades K-4 and 5-8 sections of the standards, but they were basically presented as "problem-solving activities;" these activities were not embedded in any specific mathematical context, and there was no recommendation that any specific topics should be included in the K-8 curriculum.

Discrete mathematics was included in the high school standards because its content was seen as important for high school students. However, there seemed to be no reason to introduce that content into the K-8 curriculum. This may have been partly because many mathematics educators were unfamiliar with the content of discrete mathematics, and partly because they had not recognized its value for K-8 teachers and students.

NCTM dedicated its 1991 yearbook, Discrete Mathematics Across the Curriculum $\mathrm{K}-12$, to this topic in order to give the mathematics education community a better understanding of what discrete mathematics is. The book is a compilation of articles on issues relating to discrete mathematics, the teaching of discrete mathematics in grades $\mathrm{K}-8$, and topics in discrete mathematics for grades 9-12 (graph theory, counting methods, recursion, iteration, induction, and algorithms). While the Curriculum and Evaluation Standards for School Mathematics provided a framework for creating and implementing changes in the teaching and learning of mathematics, and Discrete Mathematics Across the Curriculum K-12 provided some specific examples of how to implement these ideas, most classroom teachers were uncertain about what was discrete mathematics and how and why they should implement these topics into an already crowded curriculum. As a result, discrete mathematics was introduced in few schools.

It should be noted that the United States does not have, and most probably will never have a national curriculum, 
because of the prevailing sentiment that education should be controlled at the local level. For the same reason, none of the fifty states has a state curriculum, so that the curriculum of a school is developed within the community (that may be a large city, but may also be a small town). After the emergence of the NCTM standards and, subsequently, parallel standards documents for other content areas, the idea of "standards" became widely accepted; that is, there was agreement on the importance of specifying what students should know, understand, and be able to do at various grade levels. As a result, each state (except Iowa) has adopted state standards in each of two or more content areas (mathematics and reading/writing) and has developed statewide assessments to measure the degree to which students are meeting the standards. Note that although it is now acceptable that states set the goals of education (the "standards"), it is generally not acceptable for states to try to determine how school districts should achieve those goals. An important exception is that in a number of states (including some of the largest states, like California and Texas) a list of acceptable textbook series is prepared periodically, and public schools within the state must use a textbook series that is on that list.

Thus the presence of discrete mathematics in the NCTM standards did not necessarily mean that it would enter the curriculum of any school district. Indeed, a topic will only be included in a district's curriculum if it is included in the state's standards. In most states, this is a remote possibility since few educators, few teachers of educators, and few policy makers have much idea of what the term "discrete mathematics" refers to and why discrete mathematics is valuable for their students and teachers. The focus therefore had to be on informing educators about discrete mathematics and the opportunities it provides.

After the publication of the NCTM standards, a number of programs were developed to train teachers in the area of discrete mathematics and to engage them in meaningful discussions as to how best to implement these ideas in K-12 classrooms. Several of these programs were funded at the national level by the National Science Foundation (NSF). Our program, the Leadership Program in Discrete Mathematics (LP-DM), based at Rutgers University, which began in 1989, received funding from NSF from 1990 to 2001 (see Rosenstein \& DeBellis, 1997), and provided professional development programs for K-12 teachers; since 1995, the LP-DM has focused on K-8 teachers. A second NSF-funded program, the NCTM Standard in Discrete Mathematics Project, was based at Boston College from 1992 to 1997. Under the direction of Professor Margaret J. Kenney, it produced in its initial years a cadre of teachers of grades 7-12 who acquired a basic knowledge of discrete mathematics topics, implemented the discrete mathematics standard in their respective classrooms, and shared what they had learned with other teachers in subsequent years.

One important lesson learned early in the LP-DM was that the value of discrete mathematics was not only its content, but also the opportunity it provided to revitalize school mathematics (see Section 2).
The LP-DM is an educational component of a major research-oriented Science and Technology Center funded by NSF - the Center for Discrete Mathematics and Theoretical Computer Science, known as DIMACS, that is based at Rutgers, the State University of New Jersey, and is a collaboration involving Princeton University and major telecommunications corporations.

The K-8 LP-DM program has expanded beyond the NSF-funded programs in several ways. First, the LP-DM program continues to be replicated in other states where university mathematicians and/or mathematics educators work with the LP-DM staff to implement the LP-DM workshops at their sites, with funding from state education departments. Second, the K-8 LP-DM program has been adapted for use in the undergraduate mathematics classroom and has been offered by Valerie DeBellis to third-year college students at East Carolina University for the past five years. Third, the authors are developing (with NSF funding) a discrete mathematics text, Making Math Engaging: Discrete Mathematics for Prospective $K-8$ Teachers, for use in the undergraduate classroom, so that prospective K-8 teachers will soon have access to high quality training in the area of discrete mathematics.

Since the LP-DM has been offered to teachers at all grade levels, and those teachers have implemented discrete mathematics in their classrooms, we have been able to view discrete mathematics from a developmental perspective and to indicate what are appropriate expectations for students at all grade levels. These expectations are reflected in the K-12 standard on discrete mathematics that was incorporated into the mathematics standards adopted in New Jersey in 1996. A more detailed and comprehensive K-12 view of discrete mathematics was developed as part of the effort to create a "curriculum framework" that would assist K-12 New Jersey teachers in implementing the state's mathematics standards in their classrooms. The resulting document, "A Comprehensive View of Discrete Mathematics" (Rosenstein, 1997), appears both in the New Jersey Curriculum Framework (Rosenstein, Crown, \& Caldwell, 1997) and in Discrete Mathematics in the Schools, a DIMACS volume published jointly by the American Mathematical Society and NCTM (Rosenstein, Franzblau, \& Roberts, Eds., 1997). It provides a detailed picture of important discrete mathematics topics accessible to children at each grade level along with illustrative classroom activities that show how each recommendation in the standards can be addressed at that grade level.

In 2000, NCTM published a new version of the standards, entitled Principles and Standards for School Mathematics. On the one hand, this document (referred to as "PSSM") recommends that discrete mathematics be taught across all grade levels and that it be incorporated throughout the curriculum; on the other hand, PSSM no longer has a separate standard in discrete mathematics for grades 9-12. Three areas of discrete mathematics were highlighted as the areas that should be addressed in all grades, from pre-kindergarten through grade 12: combinatorics, iteration and recursion, and vertex-edge graphs. The term "vertex-edge graphs" was used to distinguish these graphs from those that arise in data analysis (e.g., bar graphs) or algebra (e.g., graphs of functions). 
In order to assist teachers in implementing these recommendations, NCTM's "Navigations" series ${ }^{2}$ includes a volume entitled Navigating Through Discrete Mathematics in Pre-kindergarten to Grade 12, by Eric Hart, Valerie DeBellis, Margaret Kenney, and Joseph G. Rosenstein; this book (currently under preparation) will provide content recommendations and classroom units for each grade level.

To date, at the national level, there is no clear-cut vision for discrete mathematics in K-12 schools on which American educators agree; indeed there is disagreement on almost every issue related to mathematics education, and different decisions are made in different places. Each of the fifty state departments of education operates autonomously with respect to defining its mathematics standards. States that value discrete mathematics may incorporate topics into their state standards but there is no national mandate to do so. The result is that some states have mathematics content requirements that incorporate topics of discrete mathematics and some states have only traditional mathematics content requirements. New Jersey's mathematics curriculum framework has been quite progressive in leading the way for establishing a meaningful presence of discrete mathematics in the schools. However, this came about because of unique circumstances: DIMACS and the LP-DM are based in New Jersey, and LP-DM Director Rosenstein, who also serves as Director of the policy-oriented New Jersey Mathematics Coalition, played critical roles in the development of New Jersey's mathematics standards and framework.

New Jersey's vision is not shared by many other states. Indeed, as was the case ten years ago, many educators are unaware of discrete mathematics and the opportunities that it offers for mathematics education. As a result, implementation of discrete mathematics in schools and districts often happens only when individual teachers take a leadership role in introducing discrete mathematics in their own schools.

\section{A Vision of Discrete Mathematics for K-12 Schools}

\subsection{What is discrete mathematics?}

From one perspective, discrete mathematics is an interesting set of mathematical topics. Discrete mathematics can be viewed as the three major areas listed above combinatorics, iteration and recursion, and vertex-edge graphs - that NCTM's Principles and Standards for School Mathematics says, "should be an integral part of the school mathematics curriculum" (NCTM, 2000, p. 31). It can be viewed more broadly as encompassing

\footnotetext{
${ }^{2}$ The "Navigations" series of books published by NCTM in different mathematical content areas are intended to help teachers "navigate" through the new standards and provide standards-based activities for classrooms at different grade levels. Navigating Through Discrete Mathematics PreKindergarten through Grade 12 has a chapter for each of the three content areas of discrete mathematics in PSSM -- vertexedge graphs, combinatorics, and iteration and recursion -- and within each chapter has four sections, one for each of the PreK$2,3-5,6-8$, and 9-12 grade levels, each of which discusses the content appropriate for that grade level, as well as classroom activities that convey that content to students at that grade level.
}

topics as diverse as fairness (including fair division, elections, and apportionment), information (including codes and cryptography), optimization (including scheduling and critical paths), and new directions in geometry (including fractals and taxicab geometry). As noted in the Vision Statement from the 1992 DIMACS conference, Discrete Mathematics in the Schools: How Do We Make an Impact?, "discrete mathematics needs to be introduced into the K-12 curriculum for its own sake." The Vision Statement continues:

"During the past 30 years, discrete mathematics has grown rapidly and has become a significant area of mathematics. Increasingly, discrete mathematics is the mathematics that is used by decision-makers in business and government; by workers in such fields as telecommunications and computing that depend upon information transmission; and by those in many rapidly changing professions involving health care, biology, chemistry, automated manufacturing, transportation, etc. Increasingly, discrete mathematics is the language of a large body of science and underlies decisions that individuals will have to make in their own lives, in their professions, and as citizens." (Rosenstein, Franzblau, and Roberts, 1997)

Thus, for example, students should be able to model networks using vertex-edge graphs and use graphs to solve a variety of problems - for example, linking sites using minimal connections, finding a shortest path or circuit, or applying graph coloring to conflict situations. They should be able to solve counting problems - like finding the number of different pizzas that use four out of eight toppings, and applying counting strategies to solve problems in probability. And they should be able to model and solve growth problems, such as the number of animals in a habitat, using iterative procedures.

However, from our perspective, discrete mathematics is not just mathematics content with which students should become familiar. For K-12 schools, discrete mathematics is more than just a collection of new and interesting mathematical topics.

The introductory article Discrete Mathematics in the Schools: An Opportunity to Revitalize School Mathematics (Rosenstein, 1997) in Discrete Mathematics in the Schools (Rosenstein, Franzblau, and Roberts, 1997) notes that "in two major ways, discrete mathematics offers an opportunity to revitalize school mathematics:"

"Discrete mathematics offers a new start for students. For the student who has been unsuccessful with mathematics, it offers the possibility for success. For the talented student who has lost interest in mathematics, it offers the possibility of challenge.

Discrete mathematics provides an opportunity to focus on how mathematics is taught, on giving teachers new ways of looking at mathematics and new ways of making it accessible to their students. From 
this perspective, teaching discrete mathematics in the schools is not an end in itself, but a tool for reforming mathematics education."

The article notes that this theme "grew out of the first two years of the LP-DM" because:

"Participants reported changes in their classrooms, in their students, and in themselves. Their successes taught us that discrete mathematics was not just another piece of the curriculum. Many participants reported success with a variety of students at a variety of levels, demonstrated a new enthusiasm for teaching in new ways, and proselytized among their colleagues and administrators." (Rosenstein, 1997)

Our vision of discrete mathematics is that it is a vehicle for giving teachers a new way to think about traditional mathematical topics and a new strategy for engaging their students in the study of mathematics - engage students in mathematics by involving them in discrete mathematics. Discrete mathematics offers a "new start" for teachers and a "new start" for students. ${ }^{3}$

\subsection{A perspective on teaching and learning mathematics}

Children need to be able to understand and use a variety of concepts and techniques from different areas of mathematics and to build a toolbox of problem-solving strategies from which they draw on to solve non-routine problems. Learning the basics is no longer enough. In previous generations, competency in the basic operations that were needed to run a small store (what the 1989 report Everybody Counts called "shopkeeper mathematics") may have been sufficient, but that is no longer the case. Today's children live in a technological age where they all will need to think critically, solve problems, and make decisions using mathematical reasoning and strategies.

A major obstacle to students' going beyond the basics is that their teachers often have never gone beyond the basics. Many teachers, particularly those who teach at lower grade levels, have never themselves been engaged in a single true mathematical problem-solving activity or been asked to explain or justify their reasoning. They use worksheets to provide lots of practice for their students, thinking that they are engaging their students in problem solving, but not realizing that there is a difference between a problem and an exercise. What makes a problem "a problem" is that the solution is not directly linked to previous activities. The mathematics standards expect students to go beyond the basics - in terms of additional content and a substantial increase in problem solving and reasoning, and in terms of applying the mathematics they learn in school to daily situations. Teachers who have never gone beyond the basics themselves, then, cannot reach all students as recommended in the standards, and will therefore "leave some children behind."

\footnotetext{
${ }^{3}$ The major focus of this article is on the new start for teachers provided by discrete mathematics, and in particular by the LPDM; the new start for students will be discussed elsewhere.

4 The theme of the United States government's current educational initiatives is that each child should complete school
}

Moreover, since teachers, particularly at the high school level, frequently use only direct instruction, they often do not engage their students in the learning of mathematics; students are expected to recite mathematics or apply rules and formulas, but are rarely expected to be actively engaged in figuring out the answers to more difficult questions or in discussing alternate methods of solving problems. Those students whose learning style thrives on direct instruction do well; not so, however, for the substantial numbers of students who need to build their own understanding of a concept or technique. Teachers need to learn and use a variety of instructional strategies to ensure that all students will indeed learn mathematics. This is best achieved when the teachers first experience a mathematical learning environment where all of them learn the mathematics. This perspective on teaching and learning mathematics and our view of a positive mathematical learning environment focuses on:

- mathematics as critical thinking, problem solving, sense making, and decision making;

- engaging students in the learning of mathematics; and

- $\quad$ using teaching strategies that enable all students to learn mathematics.

\subsection{What discrete mathematics offers}

We begin with an example. In our institutes, groups of participants sit around large maps of the United States, where the interiors of all the states are white, and try to determine (using chips of different colors) the minimum number of colors that must be used if you want to color each state and ensure that bordering states are colored using different colors (so that you can recognize the borders).

Note that the focus of the instruction is not on stating the Four Color Theorem that all such maps can be colored using four colors ${ }^{5}$, although that is discussed somewhat later, but on having the teachers experience for themselves the challenge of trying to determine the fewest number of colors that can be used. Through this activity, participants discover the four color conjecture and come to recognize why the Four Color Theorem makes sense. It is not so much the content of discrete mathematics that makes it a vehicle for reforming mathematics instruction, but the opportunity that the content offers to engage people in mathematical activity. ${ }^{6}$ All teachers are

with the skills and understandings necessary for his or her future. This theme is reflected in the name of the major legislation passed by the administration in 2002 entitled "No Child Left Behind." (See No Child Left Behind: A Desktop Reference, U.S. Department of Education, 2002.)

5 Until 1976, when it was proved by Kenneth Appel and Wolfgang Haken, the Four Color Theorem had been known as the "four color conjecture" for almost a hundred years. The introduction of this topic thus provides teachers and students with both an important example of newly discovered mathematics and an entrée into the development of mathematics over time.

${ }^{6}$ If instead discrete mathematics is introduced in the schools as a set of facts to be memorized and strategies to be applied routinely (see Gardiner, 1991, pg. 12), then the qualities of 
engaged in the map-coloring activity, all find it both fun and challenging, all are exercising their problem-solving and reasoning skills, and all realize that the same activity will engage all of their students, independent of grade level or ability level. Since most teachers are unfamiliar with discrete mathematics, questions like this are not even posed in traditional mathematics classes, depriving students of a rich source of problem-solving situations.

This unfamiliarity is an asset, however. It makes it possible for the teachers to participate in the program as new learners. They find that they can learn new mathematical material and solve challenging problems, and that their students can also. Discrete mathematics is a domain where interesting questions can be posed that are easily understood and that lend themselves readily to experimentation. (For example, how many paths are there between two vertices in a vertex-edge graph, and which path is the "shortest"?) In "small" situations, solutions can easily be obtained, and can be used to make conjectures about larger situations. As the number of possibilities increase, solutions are not so easily obtained, but the discussion can shift to examining strategies that can be used to obtain solutions.

Teachers in the LP-DM learn that giving students answers just to avert frustration takes away opportunities to increase problem-solving skills and the pleasure that comes from meeting challenges successfully (DeBellis \& Goldin, 1997, 1999). They learn this not by being "told" that this is true, but by being in challenging problemsolving situations where they don't give up, but rather continue to work on a problem until their frustration gives way to the "Aha!" of success.

Participants are surprised by their own mathematical ability, and begin to recognize that their students also have greater mathematical ability than they may have originally believed. In the LP-DM, teachers learn instructional strategies that work, strategies that are modeled by the program's instructors. Discrete mathematics in this program serves as a vehicle for bringing about changes in teachers' view of mathematics and how it is learned, which in turn result in changes in their classroom practices.

These kinds of experiences provide teachers with an understanding of what their students can achieve mathematically, and the tools necessary for them to become effective teachers of mathematics. Teachers are also introduced to real-world mathematical applications since techniques for coloring maps efficiently are used in solving a variety of scheduling problems, such as class scheduling, where courses that share a student have to be assigned different meeting times, or traffic light scheduling, where conflicting flows of traffic must be assigned different green light intervals. By making the mathematics relevant, these applications facilitate the sense-making process for teachers, as well as other novice mathematicians.

In our institutes, we expect, first of all, that all participants will be learners themselves, learning the mathematics that underlies the activities. Discrete mathematics

discrete mathematics as an arena for problem solving, reasoning, and experimentation are of course destroyed. provides teachers with non-intimidating access to interesting and important mathematical ideas and strategies that they can use in their classrooms to strengthen reasoning and problem-solving skills for students at all levels and of all abilities.

Providing non-intimidating access to mathematics is particularly important for elementary school teachers because many of them have negative attitudes about their own mathematical abilities that we would like to dispel so that they don't pass these attitudes on to their students. We have found the map-coloring problem to be so nonintimidating that we use it as the very first activity in the institutes for K-8 teachers. Discrete mathematics also appeals to the learning style of many elementary school teachers because of its visual and kinesthetic nature. They see discrete mathematics as "a different kind of mathematics" since they are actually doing mathematics, often for the first time in their lives, and are learning new mathematical content in a way that makes sense to them.

Our vision of what discrete mathematics can do to transform K-12 mathematics teachers, and, in turn, their classrooms has been largely formed by our experience in developing and implementing the Rutgers Leadership Program in Discrete Mathematics. In Section 3, we provide a history of that program, our model for K-8 professional development, and some concluding remarks on how our institutes have enhanced the effectiveness of $\mathrm{K}-12$ instruction.

\subsection{Problem solving approach of LP-DM}

Many K-8 teachers come to the LP-DM with a wide range of emotions about mathematics, their history with mathematics, and their perceived ability to do mathematics. Their view of problem solving involves the following: given a word problem, translate the words into mathematical symbols, solve the resulting equation using algebra (if you remember it), and state the answer using your own words. This view presupposes that a solver should "always know what to do next." If for some reason they are unable to solve a problem, it is usually attributed to the fact that they forgot how to do something. This view of problem solving is closely related to their view of how mathematics should be taught. When they begin the LP-DM, K-8 teachers typically want the instructor to tell them (or show them) how to solve the problem; they expect that the next step will be for them to go off and repeat the actions of the instructor so they can "solve" the problem themselves. They also expect to teach mathematics the same way to their students. This perspective should not be surprising, since, their experience of "higher mathematics" was typically taking a high school algebra course while in college.

We know that this limited view of problem solving impedes successful mathematical performance. If we truly want teachers to become engaged in the mathematics, we need to expose them to the emotional dynamics of problem solving and help them work through the difficulties. They need to see that doing mathematics is more than following algorithms. It involves a complex interplay between thinking and feeling that often involves wrong turns, bad decisions, and frustration, and these seemingly 
negative results can make way to positive outcomes, correct solutions, and elation (DeBellis \& Goldin, 1991; DeBellis, 1996; Goldin, 1988, 2000). Our teachers come to understand how affect appears to guide problemsolving decisions, and how powerful problem solvers use it effectively. It is through experience that they learn why persistence with mathematics is important, what roles (both positive and negative) confidence can play in solving problems, and that not knowing is inherent in any mathematical situation that is considered to be a "problem." They see that mathematical learning can be enhanced when they acknowledge what they don't know and that having mathematical integrity matters when you care about acquiring mathematical knowledge (DeBellis, 1996; DeBellis \& Goldin, 1997, 1999).

We also identify, describe, and model aspects of mathematical intimacy (DeBellis, 1996, 1998; DeBellis \& Goldin, 1997, 1999) and meta-affect (DeBellis, 1996; DeBellis \& Goldin, 1997; Goldin, 2002) so that participants can understand the interplay that such psychological constructs have on problem-solving performance. In LP-DM, as participants solve problems and demonstrate particular aspects of affect, we identify the positive problem-solving byproducts - such as willingness to take mathematical risks or remaining dedicated to solving a particularly tough problem, as well as expose negative byproducts - such as giving up, frustration, or anger. We reflect on the impact that these emotional dynamics can have on their willingness to engage in mathematical problem solving so that through the experience of solving problems and our frank discussions about their experience, they are better equipped to see, identify, and discuss the problem-solving behaviors of their students.

This is possible because of the number and variety of problems in discrete mathematics that are at the right level of difficulty. They are simply stated, easy to understand, challenging to solve, and yet can be solved. Most important, they invariably are solved, within the schedule of the program, by almost all participants. Not every participant solves every problem, but each person solves a large enough fraction of the problems so that he or she feels successful as a problem solver.

In LP-DM, we take problem-solving theory and put it into practice. We work to develop powerful affect among participants in a mathematical environment that exposes teachers to the culture of mathematics so that they are better able to pass on that culture to their students.

\section{Development of The Leadership Program in Dis- crete Mathematics}

Over the course of the past 15 years, the Rutgers Leadership Program in Discrete Mathematics (LP-DM) has provided over $1200 \mathrm{~K}-12$ teachers with an intensive, exciting, and substantial introduction to topics in discrete mathematics through extensive summer programs and follow-up sessions during the school-year. These programs were funded with three grants from the National Science Foundation (NSF) and were co-sponsored by DIMACS and the Rutgers Center for Mathematics, Sci- ence, and Computer Education (CMSCE). There have been five phases of the LP-DM:

- $\quad$ Phase 0 (1989). A two-week pilot program for high school teachers, Networks and Algorithms, that took place in the summer of 1989 with 27 high school teachers and was funded entirely by DIMACS.

- $\quad$ Phase 1 (1990-1992). A four-week summer program for high school teachers, with school-year follow-up sessions. This was funded by NSF and had two cohorts, with a total of 67 teachers.

- Phase 2 (1992-1995). A three-week summer program for high school teachers, and a parallel program for middle-school teachers, with school-year followup sessions and a two-week summer program the next year. This was also funded by NSF and had three cohorts of high school teachers and three cohorts of middle school teachers, with altogether 237 teachers (118 middle school and 119 high school).

- Phase 3 (1995-2001). A two-week summer program for K-8 teachers, with school-year follow-up sessions and a one-week summer program the next year. This was also funded by NSF and was repeated altogether 25 times (in Arizona, Massachusetts, North Carolina, Rhode Island, and Virginia, as well as New Jersey) with a total of 732 teachers.

- Phase 4 (2001-present). In this dissemination phase, the LP-DM for K-8 teachers has been replicated 10 times with a total of 204 participants in Alabama, Indiana, Massachusetts, Rhode Island, and South Dakota.

The total number of teachers who have participated in these programs since 1989 is 1267; this includes nine institutes in 1989-1994 that involved 331 middle and high school teachers, and thirty-five institutes in 1995-2003 that involved $936 \mathrm{~K}-8$ teachers.

These programs have been developed and implemented by Project Director Joseph G. Rosenstein (a mathematician), Associate Project Director Valerie A. DeBellis, (a mathematics educator), and Assistant Project Director Janice Kowalczyk (a veteran LP-DM participant and classroom teacher).

The focus of Phase 4 of the LP-DM is on dissemination and replication - that is, supporting new programs at new sites under new educational leadership across the country. This effort is made possible by a number of factors:

- the development of detailed program materials that enable mathematicians and mathematics educators to offer the LP-DM at other sites;

- the pilot replication programs at four sites (in $\mathrm{AL}$, MA, NC, and NJ in the summers of 2000 and 2001) supported by a supplementary grant from NSF that also funded a training program at Rutgers in the summer of 2000 for prospective LP-DM leaders;

- a grant from the Educational Foundation of America that provides replication programs with ongoing technical and programmatic support from Rutgers staff; and 
- $\quad$ submitting successful proposals for funding the LPDM to a number of state departments of education and higher education.

Participating teachers have a long-term involvement with the LP-DM and on-going discussions via email regarding mathematics and its implementation in their classrooms. They are expected to introduce discrete mathematics in their classrooms, incorporate discrete mathematics into their schools' curricula, and introduce their colleagues, both locally and broadly, to topics in discrete mathematics. A substantial percentage of LPDM participants have fulfilled these expectations and have remained active in LP-DM activities beyond their formal affiliation with the program.

The broader goals of LP-DM are not defined exclusively in terms of the accomplishments of the participants in the area of discrete mathematics, but also in terms of their attitudes and understandings toward mathematics and the teaching and learning of mathematics.

- By being engaged in problem-solving, they came to understand that mathematics was about solving problems, not just learning facts and procedures.

- By themselves being engaged and excited by mathematics, they learned that they could engage and excite their students with mathematics.

- By seeing mathematics as exploration, sometimes leading into uncharted territory, they could take their students on mathematical adventures.

- By seeing themselves as mathematicians, they were empowered to teach their students that when they are engaged in mathematical thought and exploration they too are mathematicians.

By 1991, we had learned that discrete mathematics was not just another interesting area of mathematics that teachers could use in their classrooms, but that it was also an excellent vehicle for changing mathematics education.

These broader goals are reflected in the design of our professional development programs, such as the K-8 teacher training program described below.

\section{A Professional Development Model for K-8 Teach- ers}

In order to appreciate the design of our model for professional development of K-8 teachers, one must first understand the population that it serves. In the United States, the usual mathematical training for prospective K-8 teachers is minimal; at best, they may have taken two undergraduate mathematics courses that focus on mathematical topics for elementary school teachers ${ }^{7}$. Prospective K-8 teachers often view mathematics exclusively as a body of knowledge, as a set of facts and procedures; their job, when they get to be teachers, will be to transmit these facts and procedures to their students. This should not be surprising, since this has likely been their experience in

\footnotetext{
7 This situation may change in the coming years, since an important national report has now recommended at least three courses for elementary school teachers and at least seven courses for middle school teachers (CBMS, 2001, p. 8).
}

learning mathematics. Many of these students attribute their lack of success in mathematics to their inability to remember all of the required facts, formulas, and techniques. In addition, many of these students report experiencing math anxiety and try to avoid the topic rather than embrace it. Yet these will become the teachers of mathematics for our children. We believe that a professional development model is needed that will change these perspectives of mathematics.

Our basic design for K-8 teachers involves four parts:

1) learn the mathematics,

2) reinforce the mathematical learning,

3) consolidate the learning, and

4) implement the mathematics.

This sequence is a fundamental part of our professional development process, since we view that it is only after $\mathrm{K}-8$ teachers and prospective $\mathrm{K}-8$ teachers experience success in learning mathematics can their anxiety be transformed into energy. We view this sequential experience as a vehicle for changing participants' attitudes about mathematics.

Recommendations from the CMBS report, "The Mathematical Education of Teachers - Part I" include that, along with building mathematical knowledge, "teachers should develop the habits of mind of a mathematical thinker and demonstrate flexible, interactive styles of teaching" (CMBS, 2001, pg. 8). The pedagogical format for our institutes models this flexible, interactive approach to instruction by using a variety of types of instructors (college mathematics faculty, college mathematics education faculty, and expert K-8 classroom teachers), by incorporating a variety of participant learning groups (individual, heterogeneous small group, homogeneous by grade-level, and whole-group), and by demonstrating a variety of instructional formats (wholegroup instruction, small-group activity, and peer presentations). We do not simply advocate these different instructional strategies; rather, we model them for the participants, ask the participants to reflect on how they were used, and discuss with them their value and their appropriate use.

Each day of our program, we cycle through the four phases below:

\subsection{Learn the mathematics}

We would like teachers to view mathematics in terms of reasoning and problem solving; in order to do that we must expect teachers to reason and solve problems. We would like teachers to recognize the applications of mathematics to the world; in order to do that we must show them how to wear eyeglasses through which they can see the world mathematically. Wrestling with a mathematical situation, what mathematicians would call "doing" mathematics, is not something with which many teachers are familiar; we need to introduce them to the idea of doing mathematics, and foster the idea that they themselves can function as mathematicians.

And, as educators of teachers, we need to provide teachers with a supportive learning environment so that they will be comfortable with working on challenging problems in mathematics, and will come to believe that they can meet high expectations. The high expectations 
that we have created for participants are reflected in the schedule of the institute itself.

Each morning, participants are involved in a two-hour content-based workshop on new mathematical topics taught by college faculty. The workshops involve a mixture of whole-group instruction and small-group activity. The pattern that is repeated throughout each workshop involves introduction of new content material, participants' working on a problem in small groups, and discussion of the problem and the material. This interactive learning environment is supported by the instructor (college faculty) and by lead teachers who work together to facilitate participants' mathematical learning. (Lead teachers are past participants in the program who have incorporated into their own classrooms both the content and the perspectives they have learned in the program.)

Although the focus of this section is the professional development model, it is important to take note of the actual content of the program, since learning the content is a significant component of the model. Each day of the program has a particular theme that is initiated in the workshop session and is echoed through the remaining sessions of the day. On the first day, building on coloring maps, we introduce vertex-edge graphs and discuss graph coloring and its applications to resolving conflicts. On the second day, the theme is Euler paths and circuits and optimal routes for snow plows and postal deliveries. On the third day, we focus on Hamilton circuits and the traveling Salesperson Problem and applications to delivering packages and optimal circuits. On the fourth day, the theme is how to connect sites efficiently (the minimum weight spanning tree problem). The fifth day is devoted to finding the best route between two sites on a map or a graph. Although the overall topic of the first five days is vertex-edge graphs and their applications, issues involving systematic listing and counting (e.g., tree diagrams and factoricals) arise each day, in preparation for the next three days, where the focus is on counting. The sixth day we focus our attention on systematic listing and counting, and in particular on applications of the addition and multiplication principles of counting. The seventh day is devoted to what we call "the choose numbers" - the number of ways of choosing $m$ out of a set of $n$ objects and the focus of the eighth day is number patterns (e.g., triangular numbers and Pascal's triangle) and iteration. This leads in to the ninth and tenth days when the focus is on patterns and iteration in both number and geometry and an investigation into fractals. Looking back on the program, at the end of the two weeks, participants are absolutely amazed at what and how much they have learned. ${ }^{8}$

\subsection{Reinforce the mathematical learning}

The workshop session is followed by a one-hour study session in which participants work in small groups on a set of "homework" problems based on the topic of the workshop. Here, participants begin developing their

\footnotetext{
${ }^{8}$ Most of the participants return for follow-up sessions during the subsequent school year, and then for another program the following summer, so their learning of new discrete mathematics doesn't end after these ten days.
}

mathematical discourse in both spoken and written forms of mathematical communication. They learn precision in language as they are left to explain and defend their solutions among peers, and they experience, often for the first time, that mathematical learning can take place "without the instructor." Each group of participants is expected to present solutions of some of the homework problems to the entire group before the morning workshop on the next day.

In these three types of sessions - workshop session, study group session, and homework session - we expect participants to suspend their role of teacher and take on the role of mathematical learner.

\subsection{Consolidate the learning}

While people with some learning styles need opportunities to talk about what they are thinking, people with other learning styles need an opportunity for quiet introspection. A teacher needs to experience learning mathematics in a variety of environments so as to be better able to understand and facilitate the variety of learning styles of the students that will appear in his or her classroom. However, we believe it is not enough to talk to teachers about learning styles in their classrooms; rather, we provide them the opportunities to experience different ways of learning in the context of doing mathematics.

Journal writing is used as a way to experience quiet introspection. Participants are provided with a ten-page "journal" in which they make daily entries regarding their mathematical learning on that day's workshop. This gives participants an opportunity to describe their experience with and understanding of the new material and to highlight areas where they are having difficulty with the material. Mathematical learning is enhanced through individual introspection, acknowledgement of content material that remains unclear, and continued discussions about that content. Teachers often think they should "know all the answers." We use journal writing to get them to discuss "what they don't know." Journals are collected near the end of each day and are reviewed by lead teachers who respond daily, in writing, to the entries. This continuous, immediate feedback is important for consolidating the mathematics - often, it takes several days to clearly understand some mathematical topic and this process allows learners to independently discuss previous topics for as long as they need.

In addition, presenting homework problems during the homework session (discussed above) also serves to consolidate the mathematics. The idea behind this session is that teachers often gain mathematical insights when they are expected to present and field questions on the mathematical material - even when they don't know all the answers. To help ease anxiety, participants make presentations in groups of two, and are encouraged to discuss not only their solution, but also how they thought through the problem - what confused them, and how they gained insight. This experience encourages a reflection on their own problem-solving behaviors and makes explicit that "doing mathematics" is often a series of decision-making steps on what to do next! 


\subsection{Implement the mathematics}

We understand that change in the classroom will not take place by simply giving teachers the opportunity to "do mathematics." Hence, the final stage in our professional development cycle includes opportunities for teachers to see teacher-tested, age-appropriate classroom demonstrations on the mathematical topics they just learned, and to discuss other ways of bringing the mathematics into their classrooms. Participants now resume their teacher role, with a new sense of mathematical accomplishment that helps foster high expectations for their students in what they are able to accomplish mathematically.

In these sessions, participants are clustered into three groups according to the grade level they teach; K-2, 3-5, and 6-8. Initially, lead teachers provide presentations on workshop topics that they have adapted and implemented into their own classrooms, and model ways of bringing the institute format into K-8 classrooms. They share materials they've made, resources they like, and samples of their student work. Following these presentations, participants share their own good ideas for implementing discrete mathematics topics into their own classrooms and discuss aspects of classroom implementation they are important to them. These incredibly popular sessions enable participants to immediately bring discrete mathematics topics into their classrooms in that they leave the institute with several ready-made classroom lessons.

At the heart of our efforts rests collaborative relationships - among mathematicians, mathematics educators, and classroom teachers. Each brings a particular perspective and focus that, when taken collectively in a training program, yields an optimal institute experience for practicing and/or prospective teachers. For instructional effectiveness, we continue to evolve our design, based on feedback from participants and the needs of individual school districts, until it meets the message of "mathematics for all" participants. This constant assessment of program activities is a routine part of our ongoing programs and models for teachers that the process of teaching never ends.

\section{Concluding Remarks}

Teaching discrete mathematics is not an end in itself, whether in our institute or in the K-8 classroom, but is a vehicle for improving understanding of all mathematical topics. By improving teachers' understanding of mathematics, it is anticipated that they will in turn improve students' understanding of mathematics. Our institutes enhance the teaching effectiveness of its participants (including their teaching of traditional mathematics topics) in the following ways:

- Allowing teachers themselves to become successful learners of mathematics - so that they can translate into their own instruction high achievable expectations for all students.

- Changing teachers' attitudes about mathematics - so that they view mathematics more in terms of problem solving and reasoning, and not exclusively in terms of remembering facts, formulas, and techniques.

- Changing teachers' instructional practices in mathe- matics - so that they use a variety of instructional formats, have students solve problems in groups, and address students with various learning styles.

- Learning how to meet mathematical challenges - so that they will understand that problems that seem difficult to solve can be solved through persistence, and so that they will recognize frustration as a normal stage of the problem-solving process ${ }^{9}$.

- Having a high level of expectation for their students. The operative assumption of our institutes is that each participant can and will solve challenging problems and learn mathematics at a level far beyond what they could have imagined and far beyond what they would teach; when they see what they accomplish, as elementary school teachers with apprehensions about mathematics and their own mathematical abilities, they come to believe that their students, that all of their students, can come to have similar accomplishments.

- Empowering participants to initiate mathematical explorations in their classrooms, and giving their students permission to travel to uncharted territory. In order to do so, participants will learn in the program that it is acceptable for them to tell students that they don't know the answer to a question. (They will of course need to develop a plan for finding the answer.)

- Learning a good deal of mathematics content, both in discrete mathematics and in traditional areas, like numbers, algebra and geometry, all of which are strongly linked to discrete mathematics.

After having these experiences, they return to their classrooms with a different view of mathematics, with a different understanding of how to teach it, and with a different perspective of what each of their own students can achieve; with this perspective, they can strive to truly leave no child behind.

\section{References}

Bondy, J.A., \& Murty, U.S.R. (1976). Graph theory with applications. New York: American Elsevier.

Conference Board of the Mathematical Sciences (CBMS). (1983). The mathematical sciences curriculum K-12: What is still fundamental and what is not. Report to the NSB Commission on Precollege Education in Mathematics, Science, and Technology. Washington, D.C.: Author.

Conference Board of the Mathematical Sciences (CBMS). (2001). The mathematical education of teachers - Part I. Washington, D.C.: Mathematical Association of America in cooperation with Providence, R.I.: American Mathematical Society.

DeBellis, V.A. (1996). Interactions between affect and cognition during mathematical problem solving: A two year case study of four elementary school children. (Doctoral Dissertation, Rutgers University). Ann Arbor, MI: University Microfilms. No. 96-30716.

DeBellis, V.A. (1998). Mathematical intimacy: Local affect in powerful problem solvers. In S. Berenson, et. al. (Eds.), Proceedings of the 12th Annual Meeting of PME-NA (North

\footnotetext{
9 The LP-DM's approach to problem solving is based on research in mathematics education by Gerald A. Goldin and Valerie A. DeBellis (Goldin, 1987, 1988, 2000; DeBellis, 1996, 1998; DeBellis \& Goldin, 1991, 1997, 1999).
} 
American Chapter of the International Group for the Psychology of Mathematics Education). (Vol. 2, pp. 435440). Columbus, OH: ERIC Clearinghouse for Science, Mathematics, \& Environmental Education.

DeBellis, V.A., \& Goldin, G.A. (1991). Interactions between cognition and affect in eight high school students' individual problem solving. In R. G. Underhill (Ed.), Proceedings of the 13th Annual Meeting of PME-NA (North American Chapter of the International Group for the Psychology of Mathematics Education). (Vol. 1, pp. 29-35). Blacksburg, VA: Virginia Polytechnic University, Division of Curriculum \& Instruction.

DeBellis, V.A., \& Goldin, G.A. (1997). The affective domain in mathematical problem solving. In E. Pehkonen (Ed.), Proceedings of the 21st Conference of the International Group for the Psychology of Mathematics Education, 2, 209216.

DeBellis, V.A., \& Goldin, G.A. (1999). Aspects of affect: Mathematical intimacy, mathematical integrity. In $\mathrm{O}$. Zaslavsky (Ed.), Proceedings of the 23rd Conference of the International Group for the Psychology of Mathematics Education, 2, 249-256.

DeBellis, V.A., \& Rosenstein, J.G. (2003). Making math engaging: Discrete mathematics for prospective $K-8$ teachers. Manuscript in preparation.

Dossey, J. (1991). Discrete mathematics: The math for our time. In M.J. Kenney \& C.R. Hirsch (Eds.), Discrete Mathematics Across the Curriculum, K-12. Reston, VA.: National Council of Teachers of Mathematics.

Dossey, J. (Ed.). (1990). Discrete mathematics and the secondary mathematics curriculum. Reston, VA., National Council of Teachers of Mathematics.

Fey, J.T., (Ed.). (1984). Computing and mathematics: The impact on secondary school curricula. Reston, VA: National Council of Teachers of Mathematics.

Gardiner, A.D. (1991). A cautionary note. In M.J. Kenney \& C. R. Hirsch (Eds.), Discrete Mathematics Across the Curriculum, K-12. Reston, VA.: National Council of Teachers of Mathematics.

Goldin, G.A. (1987). Cognitive representational systems for mathematical problem solving. In C. Janvier (Ed.), Problems of representation in the teaching and learning of mathematics (pp. 125-145). Hillsdale, NJ: Lawrence Erlbaum Associates.

Goldin, G.A. (1988). Affective representation and mathematical problem solving. In M.J. Behr, C.B. Lacampagne, \& M.M. Wheeler (Eds.), Proceedings of the 10th Annual Meeting of PME-NA (North American Chapter of the International Group for the Psychology of Mathematics Education). (pp. 1-7). DeKalb, IL: Northern Illinois University Department of Mathematics.

Goldin, G.A. (1988). The development of a model for competence in mathematical problem solving based on systems of cognitive representation. In A. Borbas (Ed.), Proceedings of the 12th Conference of the International Group for the Psychology of Mathematics Education, 2, p. 364.

Goldin, G. A. (2000). Affective pathways and representation in mathematical problem solving. Mathematical Thinking and Learning, 2 (3), 209-219.

Goldin, G.A. (2002). Affect, meta-affect, and mathematical belief structures. In G.C. Leder, E. Pehkonen, \& G. T $\overline{\text { rner }}$ (Eds.), Beliefs: A hidden variable in mathematics education? (pp. 59-72). Dordrecht: Kluwer.

Hart, E., DeBellis, V.A., Kenney, M.J., \& Rosenstein, J.G. (2003). Navigating through discrete mathematics in prekindergarten to grade 12. Manuscript in preparation.

Kenney, M.J., \& Hirsch, C.R. (Eds.). (1991). Discrete mathematics across the curriculum K-12. Reston, VA: National Council of Teachers of Mathematics.
Liu, C.L., (1968). Introduction to combinatorial mathematics. New York: McGraw-Hill.

Mathematical Sciences Education Board (1989). Everybody Counts. Washington, D.C. National Academy Press.

Maurer, S. (1983). The effects of a new college curriculum on high school mathematics. In A. Ralston \& G.S. Young (Eds.), The Future of College Mathematics: Proceedings of a Conference/Workshop on the First Two Years of College Mathematics. New York: Springer-Verlag.

National Council of Teachers of Mathematics. (1989). Curriculum and evaluation standards for school mathematics. Reston, VA: Author.

National Council of Teachers of Mathematics. (2000). Principles and standards for school mathematics. Reston, VA: Author.

Roberts, F. (1976). Discrete mathematical models. Englewood Cliffs, N.J.: Prentice Hall.

Rosenstein, J.G. (1997). A comprehensive view of discrete mathematics: Chapter 14 of the New Jersey Mathematics Curriculum Framework. In J.G. Rosenstein, D. Franzblau, \& F. Roberts (Eds.), DIMACS Series in Discrete Mathematics and Theoretical Computer Science: Discrete mathematics in the schools. (Vol. 36). American Mathematical Society and National Council of Teachers of Mathematics.

Rosenstein, J.G. (1997). Discrete mathematics in the schools: An opportunity to revitalize school mathematics. In J.G. Rosenstein, D. Franzblau, \& F. Roberts (Eds.), DIMACS Series in Discrete Mathematics and Theoretical Computer Science: Discrete mathematics in the schools. (Vol. 36). American Mathematical Society and National Council of Teachers of Mathematics.

Rosenstein, J.G., \& DeBellis, V.A. (1997). The leadership program in discrete mathematics. In J.G. Rosenstein, D. Franzblau, \& F. Roberts (Eds.), DIMACS Series in Discrete Mathematics and Theoretical Computer Science: Discrete mathematics in the schools. (Vol. 36). American Mathematical Society and National Council of Teachers of Mathematics.

Rosenstein, J.G., Caldwell, J.H., \& Crown, W.D. (1997). New Jersey mathematics curriculum framework. New Jersey Mathematics Coalition, in collaboration with the New Jersey Department of Education.

Rosenstein, J.G., Franzblau, D., \& Roberts, F. (Eds.). (1997). DIMACS Series in Discrete Mathematics and Theoretical Computer Science: Discrete mathematics in the schools. (Vol. 36). American Mathematical Society and National Council of Teachers of Mathematics.

Stanat, D., \& McAllister, D. (1977). Discrete mathematics in computer science. Englewood Cliffs, N.J.: Prentice Hall.

Tucker, A. (1980). Applied combinatorics. New York: John Wiley \& Sons.

U.S. Department of Education, Office of Elementary and Secondary Education. (2002). No Child Left Behind: A Desktop Reference. Washington, DC:

\section{Authors}

DeBellis, Valerie A., Visiting Scholar, National Computational Science Institute, Shodor Education Foundation, Inc. 923 Broad Street, Suite 100, Durham, NC 27705 USA.

Email: mdebellis@,shodor.org

Rosenstein, Joseph G., Professor, Department of Mathematics, Rutgers University, Center for Mathematics, Science, and Computer Education, 223 SERC Building, 118 Frelinghuysen Road, Piscataway, NJ 08854 USA.

Email: joer@dimacs.rutgers.edu 